\title{
Article
}

\section{Designing Multiplayer Serious Games with Science Content}

\author{
Varvara Garneli *(D), Konstantinos Patiniotis and Konstantinos Chorianopoulos
}

Department of Informatics, Ionian University, 49100 Corfu, Greece; c15pati@ionio.gr (K.P.); choko@ionio.gr (K.C.)

* Correspondence: c13garn@ionio.gr

\begin{abstract}
Serious Games (SGs) could be enriched with collaborative learning techniques, an approach that has the potential to increase the players' gaming and learning experience. However, the design of Multiplayer Serious Games (MSGs) with science content needs to be facilitated with methods and tools that provide coherent designs. This research proposes a methodology that employs the design technique of personas to effectively describe the multiplayer design patterns and the game narrative according to the content of a science school book and, at the same time, balancing the educational and the entertaining character of a SG. We evaluated the suggested methodology with two groups of professionals who were assigned with the task to design a MSG, integrating the same educational content according to the suggested methodology. The designs were qualitatively examined, confirming the potential of the Multiplayer Serious Game Methodology (MSGM) to facilitate the science content integration. We expect that the MSGM could assist groups of professionals, such as teachers and developers to create coherent MSG designs.
\end{abstract}

Keywords: serious game design; multiplayer games; collaboration; science education

Citation: Garneli, V.; Patiniotis, K.; Chorianopoulos, K. Designing Multiplayer Serious Games with Science Content. Multimodal Technol. Interact. 2021, 5, 8. https://doi.org/ $10.3390 / \mathrm{mti} 5030008$

Academic Editor: Edward Melcer

Received: 27 December 2020

Accepted: 19 February 2021

Published: 25 February 2021

Publisher's Note: MDPI stays neutral with regard to jurisdictional claims in published maps and institutional affiliations.

Copyright: (C) 2021 by the authors. Licensee MDPI, Basel, Switzerland. This article is an open access article distributed under the terms and conditions of the Creative Commons Attribution (CC BY) license (https:/ / creativecommons.org/licenses/by/ $4.0 /)$.

\section{Introduction}

Cooperative learning in science classes encourages students to work in small groups towards a common learning goal, providing the social context for active learning through connections among facts, concepts, and ideas [1,2]. On the other hand, multiplayer games facilitate attitudes, such as connection, cooperation, presence, and enjoyment among participants [3], promoting a different viewpoint in the context of Computer-Supported Collaborative Learning [4]. Therefore, Multiplayer Serious Games (MSGs) blend the potential of Serious Games (SGs) with collaborative learning techniques, an approach that has the aptitude to increase the experience within the context of Game-Based Learning and to solve some practical problems of the collaborative work, such as to regulate and evaluate student performance [5]. However, the design of MSGs with science content is a challenging process that needs to be supported in various ways. Design patterns have been identified, providing a common language of communication between stakeholders $[6,7]$ and frameworks have been proposed [8] to be used in the game design and development process. The Mechanics Dynamics Aesthetics (MDA) framework suggests an iterative series of steps; to determine the desired gameplay, to design the appropriate mechanics and to achieve the desired results through playtesting [9]. While the MDA framework can be employed for the design of digital games for entertainment, the integration of serious content is not supported. On the other hand, some models and frameworks focus on the "serious content" integration. The Learning Mechanics-Gaming Mechanics (LM-GM) Model is one such example that provides a graphical representation of the game flow to build the relationships between the pedagogical components [10]. The LM-GM is an effective but general model that supports not only the design but also the analysis and the assessment of SGs. However, the specific needs of Science Education and the representation of the multiplayer component are not sufficiently supported by the current frameworks. Human-Computer Interaction (HCI) approaches, such as personas could be employed for the development of engaging multiplayer learning experiences [11] or the writing 
of realistic roles and behaviors for game players [12]. Our aim is to apply the utility of personas to focus the design on the multiple play behaviors that may occur in MSGs with a particular orientation towards science content.

This study suggests a methodology to assist the design of MSGs in the context of Science Education, facilitating and motivating the collaborative work of professionals, such as content experts, game designers, and developers. We employed the Activity Theorybased Model of Serious Games (ATMSG), a conceptual framework that does not focus on the requirements of the development process, to represent a series of game elements, inspired by the adventure games and Role-Playing Games (RPGs), as well as the way that those elements contribute to the achievement of the educational goals [13]. The resulting gaming, learning, and instructional activities were our guide to construct the MSG's personas and to describe their roles and play behaviors. Finally, the narrative design was guided by the content of the Chemistry school book [14]. We evaluated the suggested methodology with two groups of professionals who designed an MSG, following the suggested methodology. We qualitatively assessed the two game designs, regarding the use of the methodology's building blocks.

Therefore, the purpose of this study is to assist groups of professionals who collaborate to design MSGs with science content. We suggested a methodology that focuses the design on the various play behaviors that exist in MSGs, balancing at the same time its educational and entertaining parameters. Furthermore, we hope to stimulate more research concerning the enrichment of the suggested methodology with more perspectives that support several needs and expectations of science classes.

\section{Related Work}

SGs, such as simulations, have been widely used in the context of Science Education. Such games provide students with the chance to develop intuitive understandings of abstract phenomena by manipulating the interactive variables of physical systems [15], e.g., by using a gliding simulator based on real-world physics law [16]. However, in-game experiences beyond the simulation gameplay employ different interactions to occur when players follow the predefined rules and structures [17], providing alternative educational tools to be used in science classes. Although a game is mostly a particular form of play [18], a good story could be also used, providing players with strong motivation. Narrative has a prominent role in game genres, such as Role-Playing Games (RPGs) and adventure games. At the same time, the narrative provides an excellent opportunity to integrate the content of a school book with science content in the virtual world.

\subsection{Employing Game Activities to Describe the Narrative of Serious Games with Science Content}

Adventure games and RPGs strongly rely on the implementation of a good story that could trigger and maintain student motivation. The first adventure games used only text to set the game-scene, tell the story, and challenge players with puzzles and riddles [18]. Text adventures evolved to the graphical ones which employ a graphical environment with various Non-Playable Characters (NPCs) for players to interact with. Graphical adventures also rely on a strong storyline while their gameplay provides the player with the first-person perspective of problem-solving that includes puzzles and riddles that advance the game plot. Graphical adventure games or just adventure games facilitate the presentation of the learning content in a structured and guided way, but they are particularly constraining structures that must narrate good stories $[19,20]$. On the other hand, RPGs also contain a story but in a free form as players are assigned with quests or missions, and therefore they must overcome obstacles, which rarely have a puzzle form. Players need to use skills, spells, abilities, and equipment that are acquired as the game progresses. This character's growth is necessary for players to overcome the obstacles and fulfill their quest. On the contrary, paper RPGs are not based on a pre-established storyline as players meet each other and play their character roles for years, creating stories that can be emotionally powerful and personally meaningful $[18,19]$. The adventure games 
narrative element could be used to integrate the content of a science book in a serious game but, nevertheless, the potential of the paper RPG stories could be of great interest in designing SGs with science content (See Figure 1).

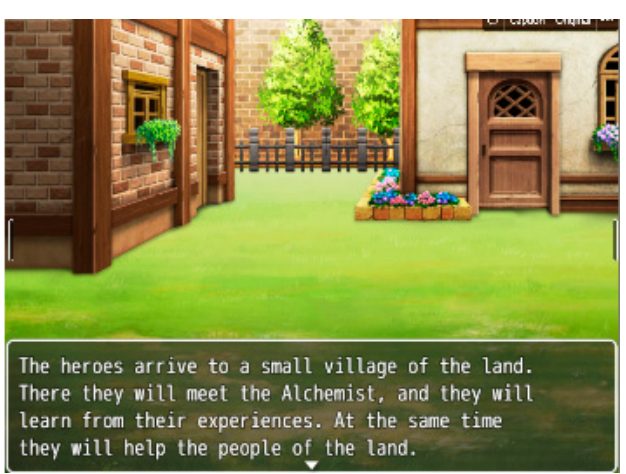

(a)

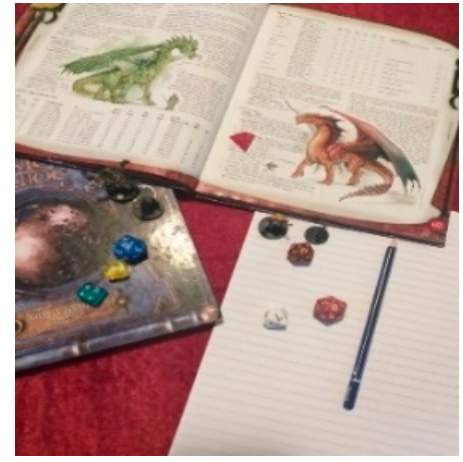

(b)

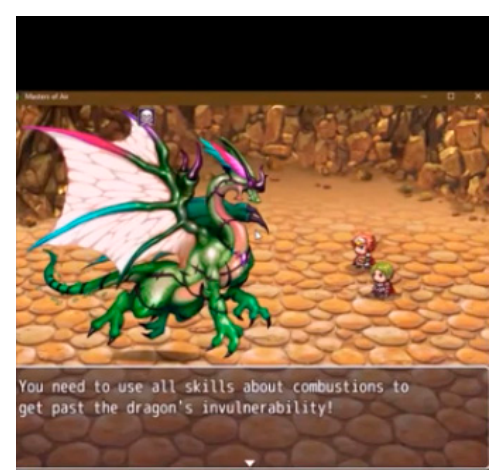

(c)

Figure 1. Narrative element is used to motivate players in the game (a) Adventure games rely on a structured and guided narrative (b) Tabletop role-playing games (RPGs) are more a social affair, creating stories that can be emotionally powerful and personally meaningful (c) Digital RPG narrative is flexible as Playable Characters need to grow in order to overcome obstacles and to advance the game plot.

The narrative integration into the game environment could be achieved by various methods, such as presenting the initial challenge, identifying obstacles, and developing puzzles, challenges, and resources. It is also important to pinpoint the necessary roles, set up the physical environment and create a backstory and the appropriate cut scenes that enable the narrative development [19]. Goals, Feedback, and Interpretation must be described with caution to facilitate the narrative design process, as the GFI Model states, extending the MDA framework by bridging the gap between narrative design, game development, story analysis, and game research [21]. However, the learning outcomes complicate the serious games' narrative design. A sequence of tasks and missions could be employed to include knowledge that can be discovered in a meaningful virtual environment where the knowledge is distributed [22]. According to the ATMSG framework, game activities that occur in the game world encapsulate gaming, learning, and instructional perspectives, and therefore, they could be used by professionals to design the narrative of an SG. On the other hand, the use of game personas has the potential to facilitate the design process of SGs [23]. We argue that those game activities that each persona can perform in the game world need careful consideration in order to result in MSGs designs that support science learning, in an entertaining way. As a result, our first research question is:

RQ 1: How a set of game activities that integrate science content in the gameplay mechanics of adventure games and RPGs can facilitate the design of MSGs?

\subsection{Employing the Multiplayer Component in the Context of Science Education}

The interactions which occur in MSGs may take the forms of competition, cooperation, or collaboration. While in competitive games, players play against each other, in cooperative games teams of players try to achieve the common goal. On the other hand, collaborative gameplay could be based on the players' complementary skills, such as knowledge, abilities, or resources which are needed for winning the game [4]. Additionally, to the decision regarding the game's multiplayer form, designers need to consider issues, such as the number of players, persistence, matchmaking, speed and flow, players' communication, social issues, and more [24]. Nevertheless, the collaborative gameplay could be supported by employing characters with different roles and abilities that need coordination and good decision-making skills and by involving difficult problems that force players to work together to solve them [25]. 
There are several efforts towards collaborative serious games design. Andreoli et al. (2017) [26] presented the FRACH framework for conceiving, designing, and evaluating collaborative Serious Games in cultural heritage. Ontological engineering has been suggested to represent collaborative learning activities [27] and taxonomies have been suggested, concerning the opportunities and risks in the context of Massively Multiplayer Online Role-Playing Games [28]. Othlinghaus-Wulhorst (2020) [29] proposed a conceptual and technical framework to design serious role-playing games for the training of specific social skills in virtual 2D learning environments, involving chatbots in dialog-centric settings. However, the existed frameworks/models do not focus on the needs and the special features of science learning. Moreover, some of them involve many technical details that do not support the collaborative work of professionals with different goals and backgrounds. Raybourn (2007) employed the HCI technique of personas to write realistic roles for the game players. We argue that personas could be used to clearly describe the multiple play behaviors that occur in MSGs with science content. Therefore, the second research question of the study is:

RQ2: Does the design technique of personas has the potential to facilitate the design of MSGs with science content?

\section{The Multiplayer Serious Games Methodology in the Context of Science Education}

The purpose of this study is to provide a useful methodology for the integration of science content in the gameplay mechanics of multiplayer games. MSGs' design needs several decisions to be taken regarding the necessary building blocks. As a start, the gameplay mechanics must be defined to determine what the players can do and what they cannot do in the virtual world. The Multiplayer Serious Game Methodology (MSGM) suggests that the players' interactions could be rather influenced by the adventure games and the RPG genres. The narrative element which is a strong element of the adventure games genre will not let unexpected issues occur during the learning process [18]. Therefore, the storyline will unfold within a virtual world that consists of a series of tile-based maps for Playable Characters (PCs) to move in and explore. PCs could interact with the various NPCs who speak to them by bringing up a panel with text, informing and guiding them while sometimes involving a selecting choice function [30]. PCs, through this interaction, understand and obtain the necessary information to progress the game, performing various activities that can be individual, cooperative, or collaborative.

The individual activities are performed by one single player who is challenged to solve a riddle or a problem, etc., in order to acquire a skill or/and an item (See Figure 2a). On the other hand, in the cooperative activities, the whole game party participates, meaning that all players are in the same place and watch the same event. In this cooperative mode, any PC can interact with an NPC, but all players are informed by reading the relevant texts, getting instructions, and sometimes answering questions. In the same way, any party member can decide to perform an assigned task but still, the other players watch the activity (See Figure 2b).

On the other hand, collaborative activities are based on the skills/items that each player individually gains during challenges. Those items and skills are stored in the player's inventory. A navigation menu opens the inventory menu which can be used by a player to see his/her own skills, items, and other statistics. Therefore, collaboration could be achieved when a challenge requires all players to use their individual skills or/and items. An example of applying collaborative gameplay is the RPG turn-based combat system. Those combats occur in separate interfaces through selections from a navigation menu [28]. The successful participation in a battle could be tightly connected to the skills that players individually have acquired. Therefore, the game party can defeat an enemy only if each player applies his/her own skills by choosing them from his/her personal inventory, ensuring the collaborative character of the game (See Figure 3). 


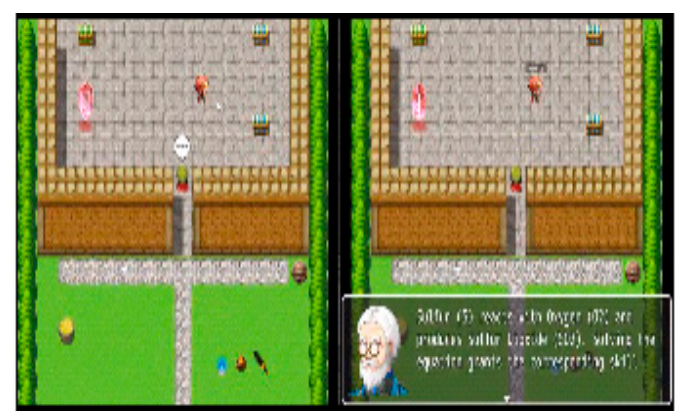

(a) Individual Activities

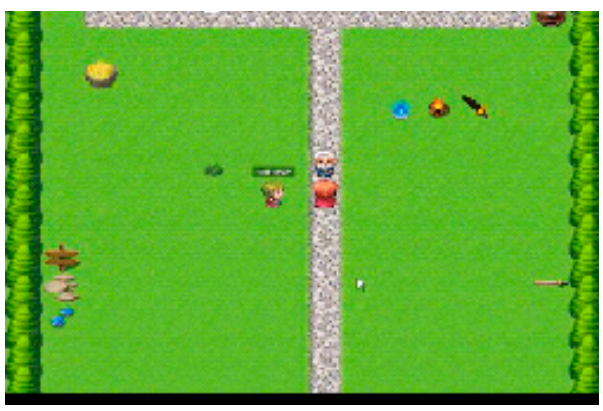

(b) Cooperative Activities

Figure 2. Examples on Cooperative and Individual Activities of MSGs (a) Harold on the left is balancing the copper oxidation equation to be rewarded with the copper oxidation skill while Therese on the right screen is assigned to individually balance the sulfur oxidation equation and acquire the sulfur oxidation skill (b) The game party is guided by an NPC to perform the experiments and observe their results, in a free form.

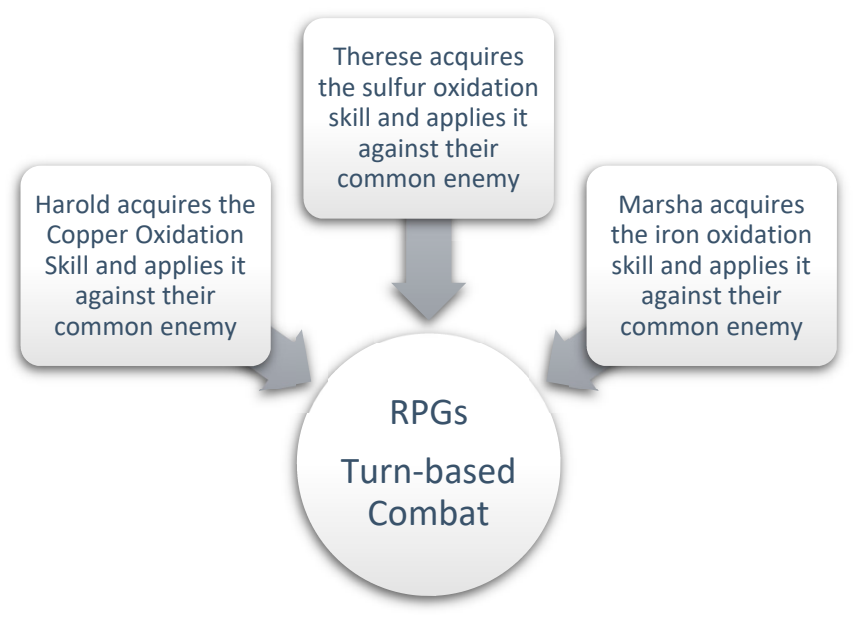

Figure 3. The RPG turn-based combat system provides a good example of using the playable character (PC) individual skills to defeat an enemy: Each player was rewarded with a different skill on the oxidations challenge. Those oxidation skills must be applied by the three players to successfully win the combat against their enemy.

Therefore, an MSG could consist of a sequence of events that involve interactions, such as dialogues with NPCs for players to acquire information and guidance, riddles solving through multiple choice questions, tasks performance using objects of the virtual world, solving puzzles, completing missions, and facing combats (See Figure 4).

The next step is to study the educational goals and the science content and to integrate the instructional methods used in the science classes for students of a particular age with the interactions that occur in the SG. Scientific learning aims to involve students in scientific investigations [31]. Therefore, science classes emphasize issues, such as how to ask and answer scientific questions and how to use analytical and scientific thinking [32]. Learning chemistry includes "naturalistic explanations based on empirical evidence, involving observation, rational argument, inference, skepticism, creativity, and the importance of being able to replicate work according to the scientific method" [33]. In such active learning settings, students direct their own learning, emphasizing strategies, such as hypothesis development, data interpretation, problem-solving, building from existing cognitive structures, and more [34,35]. NPCs are a common method in adventure games and RPGs that could be employed to present the educational content and to guide and to prompt players to perform experiments, making hypotheses, observing reactions, and concluding results in the game world. 


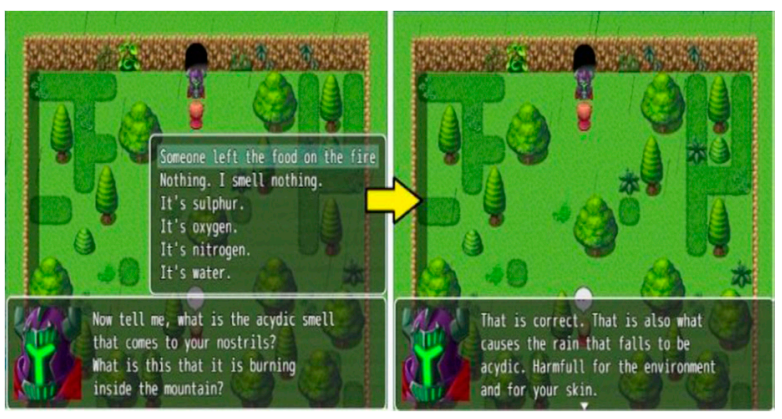

(a)

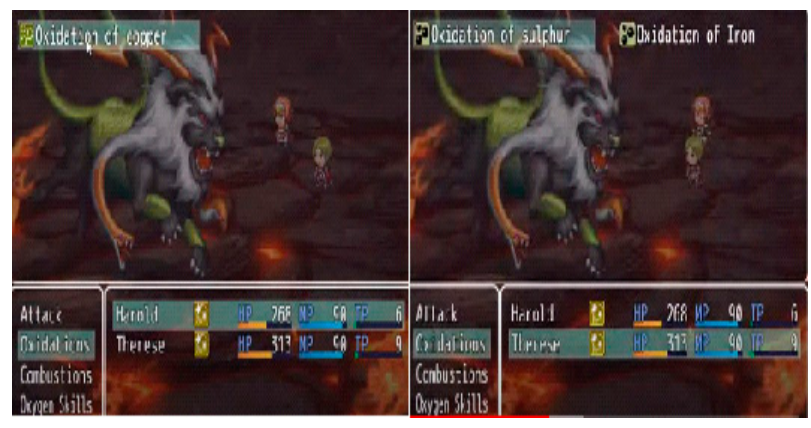

(b)

Figure 4. PCs interactions could be rather influenced by the adventure and the RPG genres. (a) The PCs need to answer a riddle and open the entrance to the next map (Adventure Games) (b) two PCs combine their unique skills on oxidations to eliminate the enemy (RPGs).

Moreover, the empowerment of student ability to link the new content to old knowledge and understanding, using the material which is provided by the teacher and the already existing knowledge, beliefs, biases, and misunderstandings should be empowered to achieve meaningful learning [36]. Adventure games and RPGs provide a set of questions in the form of riddles for students to combine their observations in the graphical environment with the content that they are taught. Each student should have an unlimited number of efforts to choose the correct answer, in a constructive trial and error method that aims to support student learning [37]. In addition, feedback could be used to empower the process. In the same viewpoint, students solve scientific problems, such as chemical equations balancing, in the same constructive trial and error method. The equation balancing could be considered as a part of puzzle-solving in the virtual world.

Science courses could benefit from examples that connect the content of the school book and the experiments in the laboratory with observations in the real world. Especially, the introductory chemistry curriculum is quite hard as many students have difficulty connecting the macroscopic world of observations with the microscopic world of atoms and molecules. Therefore, science classes usually apply practices that emphasize this connection through carefully chosen examples [38], empowering science learning and providing an excellent opportunity for the game designer to connect the content with missions' assignments.

The ATMSG conceptual framework [13] will be employed to detailed describe the activities that occur in the virtual world. The gaming activities share the same subject and tool as the learning activities. In particular, the player and the student (subjects) use the serious game (tool) but for distinct reasons. A player wants to have fun while a student might aspire to fulfill the course requirements. The instructional activities also share the same tool (serious game), but the subject is usually the game designer and/or the teacher while the motive might be to raise the learner's interest [13]. All the viewpoints need careful consideration in order to design a digital game that meets the needs and expectations of players, learners, and teachers.

Although the set of activities could be extended and enriched, the MSGM identifies five activities that include a gaming/learning/instructional perspective, describing at the same time the action that occurs, the tool, and the goal. Those activities are related to experiments performance (puzzles solution), riddles solution, problems solving (puzzles solution), content presentation, and missions that support the observation of scientific phenomena, ending with combats (See Table 1). 
Table 1. Game Activities.

\begin{tabular}{|c|c|c|c|}
\hline & Gaming & Learning & Instructional \\
\hline Action & $\begin{array}{l}\text { Players interact with items of the } \\
\text { virtual world to perform tasks and to } \\
\text { observe reactions }\end{array}$ & $\begin{array}{l}\text { Students perform and } \\
\text { observe experiments }\end{array}$ & $\begin{array}{l}\text { NPCs guide students to } \\
\text { perform experiments. }\end{array}$ \\
\hline Tool & $\begin{array}{l}\text { Avatars which move in a 2D virtual } \\
\text { world that contains items }\end{array}$ & $\begin{array}{l}\text { Educational content (text } \\
\text { and images) }\end{array}$ & $\begin{array}{l}\text { Encouragement, guidance, rewarding, } \\
\text { and summarizing results }\end{array}$ \\
\hline Goal & Puzzle solution & $\begin{array}{l}\text { Experiments performance and } \\
\text { observation, hypotheses } \\
\text { testing, conclusions }\end{array}$ & $\begin{array}{l}\text { Learning through the } \\
\text { scientific method }\end{array}$ \\
\hline Action & Players solve riddles. & $\begin{array}{l}\text { Students answer multiple-choice } \\
\text { questions based on previous } \\
\text { knowledge and observations. }\end{array}$ & $\begin{array}{l}\text { NPCs challenge players with a } \\
\text { multiple-choice riddle, commenting } \\
\text { on their choices, and concluding. }\end{array}$ \\
\hline Tool & $\begin{array}{l}\text { The character activates the } \\
\text { multiple-choice riddle and answers, } \\
\text { using a navigation menu. }\end{array}$ & $\begin{array}{l}\text { The multiple-choice question and } \\
\text { the auxiliary text }\end{array}$ & $\begin{array}{l}\text { Challenging players, providing } \\
\text { written choices, and } \\
\text { constructive feedback }\end{array}$ \\
\hline Goal & $\begin{array}{l}\text { Riddles solution and game plot } \\
\text { advancement or character evolution, } \\
\text { and special skills acquirement to be } \\
\text { used in battles }\end{array}$ & $\begin{array}{l}\text { Content repetition and } \\
\text { understanding }\end{array}$ & $\begin{array}{l}\text { Recalling previous knowledge, } \\
\text { empowerment with repetition, and } \\
\text { knowledge transfer }\end{array}$ \\
\hline Action & $\begin{array}{l}\text { Players solve puzzles to advance the } \\
\text { game plot or/and to acquire skills }\end{array}$ & $\begin{array}{l}\text { Students solve problems, such as } \\
\text { chemical equations balancing }\end{array}$ & $\begin{array}{l}\text { Challenging player, providing } \\
\text { auxiliary texts and feedback }\end{array}$ \\
\hline Tool & $\begin{array}{l}\text { A special area that is activated by the } \\
\text { character, written instructions, } \\
\text { navigation menu with choices, } \\
\text { feedback through auxiliary text }\end{array}$ & $\begin{array}{l}\text { The problem, auxiliary text, } \\
\text { and feedback }\end{array}$ & $\begin{array}{l}\text { Challenging, guiding, giving } \\
\text { feedback, encouragement, } \\
\text { concluding results }\end{array}$ \\
\hline Goal & $\begin{array}{l}\text { Puzzles solution, character evolution, } \\
\text { and special skills acquirement to be } \\
\text { used in battles }\end{array}$ & $\begin{array}{l}\text { Understanding and } \\
\text { practicing content }\end{array}$ & $\begin{array}{l}\text { Recalling previous content, practice } \\
\text { in the chemical equations' balancing }\end{array}$ \\
\hline Action & $\begin{array}{l}\text { Players explore the virtual world and } \\
\text { interact with NPCs to get information } \\
\text { and guidance }\end{array}$ & $\begin{array}{l}\text { Students are presented with the } \\
\text { educational content and } \\
\text { get instructions }\end{array}$ & $\begin{array}{l}\text { NPCs present educational content } \\
\text { and guide players }\end{array}$ \\
\hline Tool & $\begin{array}{l}\text { Characters move in the 2D virtual } \\
\text { world and interact with NPCs, } \\
\text { written info and instructions, items }\end{array}$ & $\begin{array}{l}\text { The educational content (text } \\
\text { and images) }\end{array}$ & Encouraging and motivating \\
\hline Goal & Game plot advancement & Content understanding & $\begin{array}{c}\text { Motivating students, empowerment } \\
\text { with repetition, and knowledge } \\
\text { transfer through meaningful } \\
\text { connections }\end{array}$ \\
\hline Action & $\begin{array}{l}\text { Players move in the virtual world to } \\
\text { complete their mission and defeat } \\
\text { their enemy, using their skills / items } \\
\text { Characters move in the } 2 \mathrm{D} \text { virtual }\end{array}$ & $\begin{array}{l}\text { Students observe phenomena } \\
\text { related to the acquired } \\
\text { knowledge, using examples }\end{array}$ & $\begin{array}{l}\text { NPCs present content and guide } \\
\text { players to observe, test hypotheses, } \\
\text { and conclude }\end{array}$ \\
\hline Tool & $\begin{array}{l}\text { world, NPCs, items, written } \\
\text { information and guidance, combat } \\
\text { area navigation menu }\end{array}$ & $\begin{array}{l}\text { The educational content and } \\
\text { instructions }\end{array}$ & Motivating, Encouraging \\
\hline Goal & $\begin{array}{l}\text { Mission completion and } \\
\text { combat challenge. }\end{array}$ & Content understanding & $\begin{array}{l}\text { Motivating, knowledge transfer } \\
\text { through connections with } \\
\text { related phenomena. }\end{array}$ \\
\hline
\end{tabular}

The next step is the game personas construction to illustrate the complexity of MSGs with science content. Personas are hypothetical archetypes that are used to identify the needs, objectives, and characteristics of a single user in a scenario. This technique facilitates designers to focus the goals on specific attributes [39]. We argue that the concept of personas offers us an excellent opportunity to focus the design on the different perspectives of MSGs, such as the educational, the gaming, and the multiplayer ones. 
Therefore, the MSGM suggests the construction of the in-game master persona that includes the various NPCs who guide players to advance the game plot. Those NPCs may assign a riddle or guide an experiment performance. Additionally, there are the PCs' personas that correspond to the number of players who participate in the game. However, the PCs personas describe only those activities that are performed individually by the PCs to acquire skills and/or items and to use them, according to the game plot. For example, a PC could balance the equation of copper oxidation to acquire the skill of copper oxidation that is necessary to eliminate one of the three chimera heads. On the other hand, the game party persona is constructed to illustrate those activities that the PCs perform all together, in a cooperative mode, such as the experiment performance. In this viewpoint, a PC could decide to perform one or all the steps of an experiment or just watch another PC perform them.

Moreover, each persona has also an educational perspective that needs careful consideration. As a result, for each game persona, we constructed the correspondent educational one, carefully describing the instructional and the learning activities that will be performed by the teacher persona, the student group persona, and each student persona based on the MSGM. The teacher's persona activities are described in the form of the digital RPGs' in-game master, facilitating its potential use by small student groups which work not only from distance, but also in their class to learn and practice the same curriculum, under the physical presence of one teacher (See Table 2).

Table 2. Multiplayer Serious Game Personas.

\begin{tabular}{|c|c|c|}
\hline Name & Role & Description \\
\hline In-Game Master & Teacher & $\begin{array}{c}\text { The NPCs guide students to achieve specific learning goals, according to } \\
\text { the school book of Chemistry. }\end{array}$ \\
\hline 83 & In-Game Master & $\begin{array}{c}\text { The NPCs respond to players' interaction, giving them information, } \\
\text { guiding them, challenging them with riddles and puzzles, rewarding them } \\
\text { with skills, and assigning them with missions. }\end{array}$ \\
\hline
\end{tabular}

Students work as a team in the sense that they all move on the same map and interact with NPCs for guidance. All students read the educational

Game Party Student Group

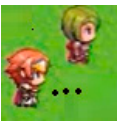

Game Party
Player 1/Student 1

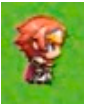

Student 1

Player 1 content, and anyone can perform an experiment or some of its steps while the others must watch the process and observe the reactions. There are also questions that must be answered by all students before the game plot can proceed.

The team of players moves from map to map together, exploring and interacting with the various NPCs who guide them. When one player performs a task, everyone is watching the process while the NPCs' instructions and information become visible to everyone and they must read them. A set of riddles could also be used to challenge the game party.

This is the persona of an individual student who is assigned specific questions to be answered and/or problems to be solved, such as chemical equations.

This is the persona of an individual player who has a particular role in the game. He/she is assigned individually with riddles or/and puzzles to be solved while their correct solution rewards him/her with skills. Those skills are stored in his/her inventory and their use is a necessary condition for the game party to complete a mission.

This is the persona of an individual student who is assigned specific questions to be answered and/or problems to be solved, such as chemical equations.

This is the persona of an individual player who has a particular role in the game. $\mathrm{He} / \mathrm{she}$ is assigned individually with riddles or/and puzzles to be solved while their correct solution rewards him/her with skills. Those skills are stored in his/her inventory and their use is a necessary condition for the game party to complete a mission. 
The detailed description of the game personas is conducted by groups of professionals, including teachers, game designers, and game developers. Teachers are responsible to illustrate the educational personas according to the educational content and goals as well as the MSGM activities. Afterwards, the game designers must focus on the gaming activities for the personas of the in-game master, the game party, and each player, ensuring the entertaining character of the game (See Table 2).

The last step requires the game designer to integrate the double character of each persona (educational and entertaining), ending in the game personas; the in-game master, the game party, and all the players' personas (See Figure 5). We argue that this process can facilitate the design and development of MSGs with science content.
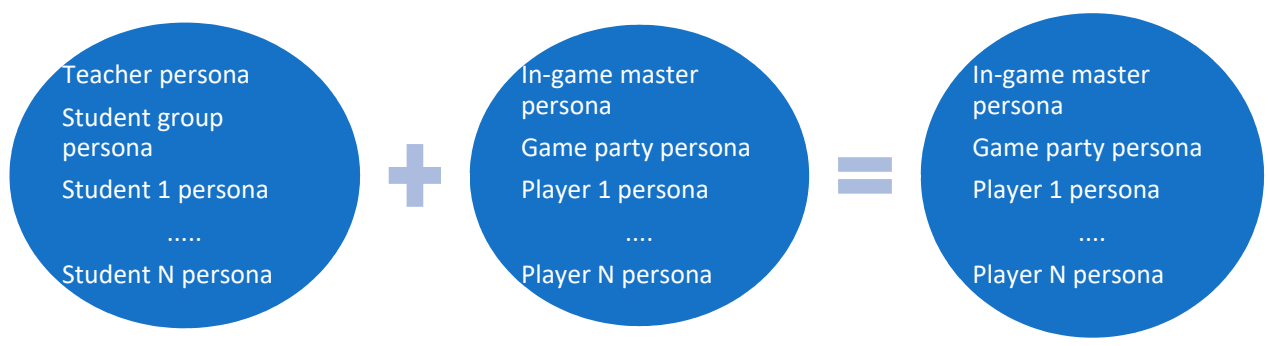

Figure 5. Game personas construction by integrating the educational with the gaming description.

In summary, the MSGM is based on several building blocks, such as the educational goals and content, the gaming, learning, and instructional activities and the game personas. Those building blocks can be used by a group of professionals to design MSGs with science content. However, this process has an iterative character due to corrections and improvements that need to be applied.

\section{Evaluation}

We performed one preliminary evaluation study to qualitatively assess the effectiveness of the MSGM and its potential to assist groups of professionals to design MSGs with science content.

\subsection{Setting}

For the needs of the evaluation process, we asked two groups of professionals (teacher, designer, developer) to design an MSG based on the educational goals and the educational content of the Chemistry student book [14] for students who are 14 years old. In particular, the game designs should support students' ability to report oxidations' examples and to balance the relevant chemical equations based on the school book's educational content (See Table 3).

The MSGM's suggested gaming, learning, and instructional activities were also available to the professionals. In the beginning, all participants were informed of the purpose and the needs of the study. Afterwards, the science teachers described each educational personas' narrative, using the suggested activities. In the following step, the game designers added the gaming personas' narrative. The next step was a synthesis of the educational and the gaming personas' narrative by the game designers, ending in the final game design. A game developer studied the game designs, commenting on the game implementation (See Figure 6). 
Table 3. Educational Content.

\begin{tabular}{|c|c|}
\hline Title & Content \\
\hline $\begin{array}{l}\text { The copper oxide } \\
\text { experiment }\end{array}$ & $\begin{array}{l}\text { We put a copper wire on the fire. When we rem } \\
\text { the fire, we find that a black substance has forr } \\
\text { of the wire. This is the copper oxide. ( } 2 \mathrm{Cu}\end{array}$ \\
\hline $\begin{array}{l}\text { The sulfur dioxide } \\
\text { experiment }\end{array}$ & $\begin{array}{l}\text { We place some sulfur powder in a porcelain ca } \\
\text { it to the fume hob, and we ignite it. Sulfur b } \\
\text { flame. The gas produced is sulfur dioxide. }\end{array}$ \\
\hline Oxidations & $\begin{array}{l}\text { Almost all elements react with oxygen and } \\
\text { compounds, the oxides. These reactions be } \\
\text { category of chemical reactions, the ox }\end{array}$ \\
\hline Iron oxide equation & $\begin{array}{l}\text { A known oxidation is that of iron, which is give } \\
\qquad\left(4 \mathrm{Fe}+3 \mathrm{O}_{2} \rightarrow 2 \mathrm{Fe}_{2} \mathrm{O}_{3}\right)\end{array}$ \\
\hline \multicolumn{2}{|c|}{ Participants Short Briefing } \\
\hline \multicolumn{2}{|c|}{ Educational Personas Narrative Description by the Teacher } \\
\hline \multicolumn{2}{|c|}{ Gaming Personas Narrative Description by the Game Designer } \\
\hline \multicolumn{2}{|c|}{ Personas' Narrative Synthesis by the Game Designer } \\
\hline Game D & per Confirmation \\
\hline
\end{tabular}

Figure 6. The Game Design Process.

\subsection{Participants}

The participants of the evaluation process conducted in Greece and involved two groups of professionals (See Table 4).

Table 4. Participants Demographic Information.

\begin{tabular}{ccc}
\hline & Group 1 & Group 2 \\
\hline Males & 3 & 2 \\
Females & 0 & 1 \\
N & 3 & 3 \\
Mean Age & 42.33 & 38.53 \\
SD Age & 8.737 & 9.452 \\
Mean Experience & 7 & 7.67 \\
SD Experience & 4.359 & 8.327 \\
\hline
\end{tabular}

Each group consisted of one science teacher, one game designer, and one developer with experience in the development of SGs. The science teachers were one male and one female with bachelor's degrees and more than 10 years of teaching experience in science classes. Teachers had no previous experience in playing video games. The game designers and the game developer were males with game design/development experience of 1-4 years. They all had a master's degree and one of them had additionally a doctorate. They were all game players, and they used to spend time playing video games for entertainment, such as real-time strategy games, action games, MMORPGs, and more. 


\subsection{Measures and Data Analysis}

This study suggests the MSGM to assist groups of professionals to design MSGs with science content in a practical and easy-to-use way, avoiding potential misunderstandings and confusions. We asked the two groups of professionals to design a game about the oxidations, according to a given set of educational goals and content as well as a set of available gaming, learning, and instructional activities. We provided them with an empty form to be completed [40]. We investigated the methodology's ability to guide the design of MSGs with science content by qualitatively examining the two game designs which integrate the same educational content. We performed a deductive content analysis [41], examining the MSGM's building blocks present in the two game designs (See Table 5).

Table 5. Coding Schema.

\begin{tabular}{|c|c|c|}
\hline Building Blocks & Coding Rules & Examples \\
\hline Educational Goals & $\begin{array}{l}\text { Yes, if the educational goals are fulfilled } \\
\text { or explanatory comments in the opposite } \\
\text { case }\end{array}$ & $\begin{array}{l}\text { "The game party perform the copper } \\
\text { oxidation experiment, observing the } \\
\text { reaction of a copper item on } \\
\text { fire" / "Harold balances the copper } \\
\text { oxidation equation" }\end{array}$ \\
\hline Educational Content & $\begin{array}{l}\text { Yes, if all the educational content of the } \\
\text { Chemistry Book is used or explanatory } \\
\text { comments in the opposite case }\end{array}$ & \\
\hline Content presentation & $\begin{array}{l}\text { Yes or no, depending on the existence of } \\
\text { content presentations by the NPCs }\end{array}$ & $\begin{array}{l}\text { “The NPC informs players that all } \\
\text { elements react with oxygen and form } \\
\text { chemical compounds, the oxides". }\end{array}$ \\
\hline $\begin{array}{c}\text { Experiments performance and } \\
\text { observation }\end{array}$ & $\begin{array}{l}\text { The number of players' reactions with } \\
\text { items to observe the results }\end{array}$ & "A PC puts a copper item on a fire" \\
\hline Riddles solving & $\begin{array}{l}\text { The number of riddles that must be } \\
\text { answered based on previous knowledge } \\
\text { and/or observations }\end{array}$ & $\begin{array}{l}\text { "An NPC assigns the game party with a } \\
\text { riddle related to the copper oxidation } \\
\text { observation to be solved" }\end{array}$ \\
\hline Puzzles solving & The number of puzzles to be solved & $\begin{array}{l}\text { "An NPC assigns Harold to balance the } \\
\text { equation of the copper oxidation" }\end{array}$ \\
\hline $\begin{array}{l}\text { Examples to connect the content with } \\
\text { "real-world" observations }\end{array}$ & $\begin{array}{l}\text { The number of examples that connect the } \\
\text { content with observations in the real } \\
\text { world and their description. }\end{array}$ & $\begin{array}{l}\text { "The heroes lost a key made of copper. } \\
\text { They found it among the ashes, but its } \\
\text { color has changed" }\end{array}$ \\
\hline Cooperation & $\begin{array}{l}\text { Yes or no, depending on the presence of } \\
\text { the game party persona, as it is described } \\
\text { in the MSGM }\end{array}$ & $\begin{array}{l}\text { "The game party observes the copper } \\
\text { oxidation experiment; one of the players } \\
\text { finds a copper item and takes it to the } \\
\text { fire." }\end{array}$ \\
\hline Collaboration & $\begin{array}{l}\text { Yes or no, depending on the existence of } \\
\text { the PCs personas who acquire } \\
\text { skills / items to be complimentarily used } \\
\text { from the game party to complete the } \\
\text { mission }\end{array}$ & $\begin{array}{l}\text { "Harold is rewarded with the copper } \\
\text { oxidation skill, Therese is rewarded with } \\
\text { the sulfur oxidation skill, and Marsha is } \\
\text { rewarded with the iron oxidation skill, } \\
\text { after balancing the corresponding } \\
\text { chemical equations. All skills are } \\
\text { required to eliminate the chimera" }\end{array}$ \\
\hline Mission & $\begin{array}{l}\text { Description of missions that are } \\
\text { connected to the narrative or no if no } \\
\text { missions are included. }\end{array}$ & $\begin{array}{l}\text { "The heroes need to find the enemy and } \\
\text { eliminate her power to claim an item." }\end{array}$ \\
\hline Narrative & $\begin{array}{l}\text { Yes or no depending on the presence of a } \\
\text { certain structure based on the educational } \\
\text { content to be covered and the educational } \\
\text { examples. }\end{array}$ & $\begin{array}{l}\text { "Experiments performance and } \\
\text { observation-riddles solution-equations } \\
\text { balancing-mission to be completed" }\end{array}$ \\
\hline
\end{tabular}


At first, we checked the game designs whether the educational goals were fulfilled and the educational content from the Chemistry school book was used. Then, we checked if the professionals used the suggested learning and instructional activities to integrate the content, combining them with the corresponding gaming ones. Therefore, we labeled the five MSGM activities and checked their presence in the game designs: content presentation, experiment performance and observation, riddle-solving, puzzle-solving, and examples to connect the content with real-world observations. Another important point was to check the use of the cooperative and the collaborative patterns. Finally, we checked the use of the suggested examples in the assigned missions and the applied storyline to motivate the players.

\section{Results}

Two groups of professionals worked together to design an MSG about oxidations, according to the content of the Chemistry school book [14]. Each game design was based on the MSGM, describing in detail the sequence of events (narrative) that will occur in the virtual world for each game persona.

The first game introduces players with a problem, motivating them to play; the surroundings of a village are seriously damaged by the phenomenon of acidification due to the dragon's breath. The farmer explains to the three heroes the problem they are facing and proposes a solution. He is assigning them with the mission to find the dragon's cave and eliminate him to save the village and the surrounding area. Therefore, the narrative has a significant role in the game, and it is cleverly combined with the educational goals and content of the school book. However, the teacher decided not to include the iron oxidation example and equation. Instead, he proposed three examples to be used by the designer to connect the educational content with phenomena of everyday life, such as the phenomenon of acidification, and more (See Table 5). The designer used those examples to make the game scenario according to the suggested by the MSGM gaming elements, such as exploration, puzzles and riddles solution, mission assignment, interaction with objects, and skills acquisition. An important issue is the implementation of the multiplayer design patterns. Players are assigned riddles and puzzles to be solved individually. The players' effort was rewarded with items while each item has a unique and significant role in the mission completion. Therefore, the collaborative pattern is guaranteed in the game. Moreover, the players also participate in several learning and gaming activities, in a cooperative way. Finally, a developer checked the game design and considered that it could be developed with a game engine. We argue that the professionals of the first group successfully applied the MSGM's building blocks.

The second game design also introduces the players with a problem; the heroes are captured by two goblins and must escape to save their lives. The heroes are trying to confuse the goblins, starting a conversation about oxidations. The starting point for their conversation is the yellowed leaves on the ground as well as a rusty iron piece, which are both oxidation examples that can be observed during the heroes' walk in the forest. The group is trying to ignore the goblins while at the same time they are trying to pay attention to their tutor. The narrative assigns players with individual puzzles (equations) that award them with items. Those items are used to complete their mission to escape from the goblins, supporting the group's collaboration. The rest of the educational content is also presented in a cooperative mode by tutor's presentations and comments, experiments observations through the characters' interaction with various items, and equations' balancing. Finally, content understanding is also supported by riddles that need the combination of players' observations with previous knowledge in a cooperative mode. The narrative of this game follows the Chemistry School book's structure. Finally, a developer also checked the game design and considered that it could be developed. The professionals of the second group successfully applied the MSGM, using the suggestions of the building blocks (See Table 6). 
Table 6. Implementation of the Design Methodology in Case Study 1.

\begin{tabular}{|c|c|c|}
\hline Building Blocks & Group 1 & Group 2 \\
\hline Educational goals & $\sqrt{ }$ & $\sqrt{ }$ \\
\hline Educational content & $\begin{array}{l}\text { The chemical equation for the iron oxidation is } \\
\text { not included }\end{array}$ & $\sqrt{ }$ \\
\hline Content Presentation by NPCs & $\sqrt{ }$ & $\sqrt{ }$ \\
\hline $\begin{array}{l}\text { Experiments performance } \\
\text { and observation }\end{array}$ & 2 & 2 \\
\hline Riddles solution & 5 & 2 \\
\hline Equations solution (puzzles) & 2 & 3 \\
\hline $\begin{array}{c}\text { Examples to connect the } \\
\text { content with real } \\
\text { world observations }\end{array}$ & $\begin{array}{l}\text { A copper wire that is not all } \\
\text { covered with plastic } \\
\text { The smell near the } \\
\text { smell springs } \\
\text { The phenomenon of } \\
\text { acidification and its influence } \\
\text { on the ancient ruins }\end{array}$ & $\begin{array}{c}\text { The chlorophyll oxidation } \\
\text { The iron oxidation in } \\
\text { the forest }\end{array}$ \\
\hline Collaborative design pattern & $\sqrt{ }$ & $\sqrt{ }$ \\
\hline Mission & $\begin{array}{l}\text { Players must save the village and the } \\
\text { surroundings from the dragon's breath }\end{array}$ & $\begin{array}{c}\text { Players must escape from the goblins to save } \\
\text { their lives }\end{array}$ \\
\hline Narrative & $\sqrt{ }$ & $\sqrt{ }$ \\
\hline
\end{tabular}

\section{Discussion}

SG design is a challenging process that aims to provide learners with educational tools which have the potential to get them to learn and master something that is long and challenging, in an entertaining way [42]. The aim of this work is to suggest and evaluate a methodology that could assist the design of MSGs in the context of Science Education, facilitating and motivating the collaborative work of professionals, such as teachers, game designers, and game developers. The evaluation process involved two groups of professionals who designed an MSG about oxidations, using the appropriate educational content from the Chemistry school book for students who are 14 years old.

\subsection{Employing Game Activities to Describe the Narrative of Serious Games with Science Content}

The narrative has a defining role in the design of adventure games, prompting players to solve problems under the guidance of the various NPCs in order to advance the game plot [15]. Both game designs present the content, prompt players to perform and observe the experiments that are described in the Chemistry school book, and balance the related chemical equations. For each experiment, both student groups are assigned riddles to be answered based on their observations and their prior knowledge. The multiple-choice questions are similar in both games with small differences for the wrong choices. The educational content was integrated according to the educational goals, using the MSGM game activities. The developer expert considered that the game designs have no potential technical issues for the game development process.

Although both game designs connected the educational content with observations in the real world, assigning players with missions to complete, there were some differences. The teacher of the first group provided more examples to connect the content with realworld observations. That was used by the game designer to give the game a richer context and narrative. In particular, the PCs were assigned with the task to explore new maps and to find items, observing phenomena and answering more riddles. Such a strong narrative theme has the potential to enrich and empower student learning in the virtual world [38]. The second designer was provided with two examples and extra content presentation suggestions by the teacher. Although he used those examples, placing the event in the forest and giving the NPC the chance to speak about chlorophyll and iron oxidations, he gave a more active character to the SG. He employed the content presentation activities as a technique used by the NPC not only to provide players with useful information 
according to their observations but also to confuse the goblins which were bothering and even threatening the PCs.

Teachers of both groups employed game activities and the technique of personas to promote science learning, focusing on the educational perspective. They also suggested appropriate examples that facilitate content understanding, giving game designers the opportunity to design the MSG's missions. Finally, the game activities supported game designers to integrate the educational content in particular gameplay mechanics, inspired by the adventure games and the RPGs, such as riddles and puzzles solution, character evolution, mission assignment, and more. Therefore, the MSGM activities supported professionals' effort to collaborate, designing MSGs that facilitate scientific learning in an entertaining way.

\subsection{Employing the Multiplayer Component in the Context of Science Education}

Multiplayer educational games have the potential to increase learning gains and student engagement compared to individual learning game experiences [5]. The two game designs successfully applied the cooperative and collaborative modes, according to the suggestions of the MSGM. Both game designs ended in the description of five personas, the in-game master persona, the game party persona, and three more personas, one for each PC. The use of personas to describe the role and the behavior of the game party facilitated the implementation of the cooperative mode in both game designs. This cooperative character supports peer learning but in a freer form. More notably, the clear description of the skills/items that each PC individually acquires supported the collaborative character of the game designs. Although the RPG turn-based battle system was not employed, in both game designs, the game party can complete the assigned mission only if each player uses the items that they individually have gained, during his/her navigation in the game world. Therefore, we argue that the MSGM and the design technique of personas have the potential to facilitate the cooperative and collaborative character of MSGs.

The game activities of the MSGM were based on the ATMSG conceptual framework and the needs of Science Education, facilitating the science content integration in gameplay mechanics inspired by the adventure games and the RPGs, according to the educational goals. Moreover, the design technique of personas was successfully applied to define the individual behavior of each PC and the behavior of the game party, clearly describing the multiplayer design patterns.

The MSGM was based on the game designs that the groups of professionals made. Therefore, the study's data are freely available, avoiding any threats of interpretation validity. However, to carry out the MSGM evaluation, we were based on introductory chemistry content for students who are 14 years old. Therefore, the evaluation is limited regarding the age of the learners and the type of integrated science content. Although the MSGM promotes the integration of science methods, such as hypothesis development, data interpretation, problem-solving, building from existing cognitive structures $[34,35]$, and bridges the experiences between the classroom and the outside world [43], further research should be conducted regarding the integration of more types of science content, such as physics that is addressed to different student ages. Another limitation of the study is that only one of the professionals who participated in the study was female. Although we tried to include more females in the evaluation process, we did not manage to succeed in gender diversity. More notably, the game designers were limited by the teachers' decisions and maybe by their own gaming preferences. Such limitations could be dealt by providing more constraints to the number of examples that will be used to connect the content with real-world observations and the available time.

Finally, the overall picture of the MSGM evaluation should be completed by considering the game development process too while the produced games must also be evaluated with students and their teachers, assessing parameters, such as student performance and social interactions, while valuable information could be gathered by the opinion of educators and course designers. 


\section{Conclusions}

This study suggests a methodology to be used by professionals, such as content experts, course designers and game designers who work together to design MSGs in the context of Science Education. The multiplayer character and the narrative are facilitated by the design technique of personas while the learning and instructional activities that occur in science classes are connected to a series of gaming activities, inspired by adventure games and RPGs.

We argue that the MSGM has the potential to support the collaborative work of professionals with different backgrounds, goals, and needs, giving them a common language to communicate with. Therefore, MSGM could be considered as an effective design tool that facilitates the collaborative design of MSGs with science content, enriching science classes with alternative learning settings. Such efforts blend the entertaining character of video games with collaborative learning techniques that engage small groups of students to work together toward a common goal.

Author Contributions: Conceptualization, K.C., V.G.; Project Administration, Funding Acquisition, and Supervision, K.C.; Writing Original Draft and Reviews Editing, K.C. and V.G., Methodology, V.G. and K.P.; Data Curation and Analysis, Investigation, and Validation, V.G. All authors have read and agreed to the published version of the manuscript.

Funding: This research is co-financed by Greece and the European Union (European Social FundESF) through the Operational Programme «Human Resources Development, Education and Lifelong Learning 2014-2020» in the context of the project "Designing a Multiplayer Role-Playing Game with Science Content" (MIS 5047802)".

Institutional Review Board Statement: The study was conducted according to the guidelines of the Declaration of Helsinki, and approved by the Institutional Review Board of Ionian University (ELKE) 28 January 2020.

Informed Consent Statement: Written informed consent has been obtained from the patient(s) to publish this paper.

Data Availability Statement: The data presented in this study are available on request from the corresponding author. The data are not publicly available due to their use for further research reasons.

Acknowledgments: We would like to thank the content experts, the game designers, and the game developers who voluntarily participated in the MSGM evaluation.

Conflicts of Interest: The authors declare no conflict of interest.

\section{References}

1. Johnson, R.T.; Johnson, D.W. Cooperative learning in the science classroom. Sci. Child. 1986, 24, 31-32.

2. Lin, E. Cooperative learning in the science classroom. Sci. Teach. 2006, 73, 34-39.

3. Vella, K.; Koren, C.J.; Johnson, D. The impact of agency and familiarity in cooperative multiplayer games. In Proceedings of the CHI PLAY '17: Annual Symposium on Computer-Human Interaction in Play, Amsterdam, The Netherlands, 15-18 October 2017; Association for Computing Machinery: New York, NY, USA, 2017; pp. 423-434.

4. Wendel, V.; Gutjahr, M.; Göbel, S.; Steinmetz, R. Designing collaborative multiplayer serious games for collaborative learningescape from wilson island-a multiplayer $3 \mathrm{~d}$ serious game for collaborative learning in teams. In Proceedings of the 4th International Conference on Computer Supported Education, Proto, Portugal, 16-18 April 2012; pp. $199-210$.

5. Nickel, A.; Barnes, T. Games for CS education: Computer-supported collaborative learning and multiplayer games. In Proceedings of the Fifth International Conference on the Foundations of Digital Games, Monterey, CA, USA, 19-21 June 2010; Association for Computing Machinery: New York, NY, USA, 2010; pp. 274-276.

6. Björk, S.; Holopainen, J. Games and design patterns. In The Game Design Reader; Salen, K., Zimmerman, E., Eds.; The MIT Press: Cambridge, MA, USA; London, UK, 2006; pp. 410-437.

7. Ašeriškis, D.; Damaševičius, R. Gamification patterns for gamification applications. Procedia Comput. Sci. 2014, 39, 83-90. [CrossRef]

8. Slimani, A.; Sbert, M.; Boada, I.; Elouaai, F.; Bouhorma, M. Improving serious game design through a descriptive classification: A comparation of methodologies. J. Theor. Appl. Inf. Technol. 2016, 92, 130-143. 
9. Hunicke, R.; LeBlanc, M.; Zubek, R. MDA: A formal approach to game design and game research. In Proceedings of the AAAI Workshop on Challenges in Game AI, San Jose, CA, USA, July 2004; p. 1722. Available online: https://users.cs.northwestern. edu/ \{\}hunicke/MDA.pdf (accessed on 10 December 2020).

10. Arnab, S.; Lim, T.; Carvalho, M.B.; Bellotti, F.; De Freitas, S.; Louchart, S.; Suttie, N.; Berta, R.; De Gloria, A. Mapping learning and game mechanics for serious games analysis. Br. J. Educ. Technol. 2015, 46, 391-411. [CrossRef]

11. Raybourn, E.M. Applying simulation experience design methods to creating serious game-based adaptive training systems. Interact. Comput. 2007, 19, 206-214. [CrossRef]

12. Tychsen, A.; Canossa, A. Defining personas in games using metrics. In Proceedings of the 2008 Conference on Future Play Research, Play, Share-Future Play '08, Toronto, ON, Canada, 3-5 November 2008; Association for Computing Machinery: New York, NY, USA, 2008; pp. 73-80.

13. Carvalho, M.B.; Bellotti, F.; Berta, R.; De Gloria, A.; Sedano, C.I.; Hauge, J.B.; Hu, J.; Rauterberg, M. An activity theory-based model for serious games analysis and conceptual design. Comput. Educ. 2015, 87, 166-181. [CrossRef]

14. Chemistry, 2nd Grade of the Medium School, the Atmospheric Air. Available online: http://ebooks.edu.gr/ebooks/v/html/85 47/2206/Chimeia_B-Gymnasiou_html-empl/index3.html (accessed on 10 December 2020).

15. Gredler, M.E. Games and simulations and their relationships to learning. Handb. Res. Educ. Comm. Technol. $2004,2,571-581$.

16. Buzys, R.; Maskeliūnas, R.; Damaševičius, R.; Sidekerskienè, T.; Woźniak, M.; Wei, W. Cloudification of virtual reality gliding simulation game. Information 2018, 9, 293. [CrossRef]

17. Salen, K.; Tekinbaş, K.S.; Zimmerman, E. Rules of Play: Game Design Fundamentals; MIT Press: Cambridge, MA, USA; London, UK, 2004.

18. Costikyan, G. Where stories end and games begin. Game Dev. 2000, 7, 44-53.

19. Dickey, M.D. Game design narrative for learning: Appropriating adventure game design narrative devices and techniques for the design of interactive learning environments. Educ. Technol. Res. Dev. 2006, 54, 245-263. [CrossRef]

20. Reuter, C.; Wendel, V.; Göbel, S.; Steinmetz, R. Multiplayer adventures for collaborative learning with serious games. In Proceedings of the 6th European Conference on Games Based Learning, Cork, Ireland, 4-5 October 2012; pp. 416-423.

21. Cardona-Rivera, R.E.; Zagal, J.P.; Debus, M.S. GFI: A Formal Approach to Narrative Design and Game Research. In Constructive Side-Channel Analysis and Secure Design; Springer International Publishing: Berlin, Germany, 2020; pp. 133-148.

22. Arnab, S.; de Freitas, S.; Bellotti, F.; Lim, T.; Louchart, S.; Suttie, N.; De Gloria, A. Pedagogy-driven design of Serious Games: An overall view on learning and game mechanics mapping, and cognition-based models. Serious Games Instit. 2012. [CrossRef]

23. Pruitt, J.; Grudin, J. Personas: Practice and theory. In Proceedings of the Conference on Designing for User Experiences, San Francisco, CA, USA, 6-7 June 2003; Association for Computing Machinery: New York, NY, USA, 2003; pp. 1-15.

24. Wendel, V.; Konert, J. Multiplayer serious games. In Lecture Notes in Computer Science; Springer International Publishing: Berlin, Germany, 2016; pp. 211-241.

25. Zagal, J.P.; Rick, J.; Hsi, I. Collaborative games: Lessons learned from board games. Simul. Gaming 2006, 37, 24-40. [CrossRef]

26. Andreoli, R.; Corolla, A.; Faggiano, A.; Malandrino, D.; Pirozzi, D.; Ranaldi, M.; Santangelo, G.; Scarano, V. A framework to design, develop, and evaluate immersive and collaborative serious games in cultural heritage. J. Comput. Cult. Herit. 2018, 11, 1-22. [CrossRef]

27. Challco, G.C.; Moreira, D.A.; Bittencourt, I.I.; Mizoguchi, R.; Isotani, S. Personalization of gamification in collaborative learning contexts using ontologies. IEEE Lat. Am. Trans. 2015, 13, 1995-2002. [CrossRef]

28. Sanders, B.; Marchang, J. A novel taxonomy of opportunities and risks in massively multiplayer online role playing games. In Proceedings of the 8th International Conference on Theory and Practice of Electronic Governance, Montevideo, Uruguay, 1-3 March 2016; Association for Computing Machinery: New York, NY, USA, 2016; pp. 90-98.

29. Othlinghaus-Wulhorst, J.; Hoppe, H.U. A technical and conceptual framework for serious role-playing games in the area of social skill training. Front. Comput. Sci. 2020, 2. [CrossRef]

30. Osborn, J.C.; Samuel, B.; Summerville, A.; Mateas, M. Towards general rpg playing. In Proceedings of the Thirteenth Artificial Intelligence and Interactive Digital Entertainment Conference, Utah, UT, USA, 5-9 October 2017.

31. Minner, D.D.; Levy, A.J.; Century, J. Inquiry-based science instruction-what is it and does it matter? Results from a research synthesis years 1984 to 2002. J. Res. Sci. Teach. 2010, 47, 474-496. [CrossRef]

32. Handelsman, J.; Ebert-May, D.; Beichner, R.; Bruns, P.; Chang, A.; DeHaan, R.; Wood, W.B. Scientific teaching. Sci. N. Ser. 2004, 304, 521-522. [CrossRef]

33. Holbrook, J. Making chemistry teaching relevant. Chem. Educ. Int. 2005, 6, 1.

34. Anderson, R.D. Reforming science teaching: What research says about inquiry. J. Sci. Teach. Educ. 2002, 13, 1-12. [CrossRef]

35. Saunders, W.L. The constructivist perspective: Implications and teaching strategies for science. Sch. Sci. Math. 1992, 92, 136-141. [CrossRef]

36. Johnstone, A.H. Chemistry teaching-science or alchemy? 1996 brasted lecture. J. Chem. Educ. 1997, 74. [CrossRef]

37. Chorianopoulos, K.; Giannakos, M. Design principles for serious video games in mathematics education: From theory to practice. Int. J. Serious Games 2014, 1. [CrossRef]

38. Gillespie, R.G. Commentary: Reforming the general Chemistry textbook. J. Chem. Educ. 1997, 74. [CrossRef]

39. Cooper, A. The Inmates Are Running the Asylum; Springer International Publishing: Berlin, Germany, $1999 ;$ p. 17.

40. Evaluation Map. Available online: https://docs.google.com/spreadsheets/d/11061kKrYTokrguWHRkrRrmEWGUDD3r70s116 DHevl2Y / edit?usp=sharing (accessed on 22 December 2020). 
41. Elo, S.; Kyngäs, H. The qualitative content analysis process. J. Adv. Nurs. 2008, 62, 107-115. [CrossRef]

42. Gee, J.P. What video games have to teach us about learning and literacy. Comput. Entertain. 2003, 1, 20. [CrossRef]

43. Klopfer, E.; Yoon, S. Developing games and simulations for today and tomorrow's tech savvy youth. TechTrends $2005,49,33-41$. [CrossRef] 